\title{
Epstein-Barr Virus Encephalitis with a Reversible Splenial Lesion
}

Satoru Takeuchi ${ }^{1}$, Yoshio Takasato ${ }^{2}$ and Hiroyuki Masaoka ${ }^{2}$

Key words: Epstein-Barr virus, splenium, encephalitis

(Intern Med 51: 341-342, 2012)

(DOI: 10.2169/internalmedicine.51.6768)
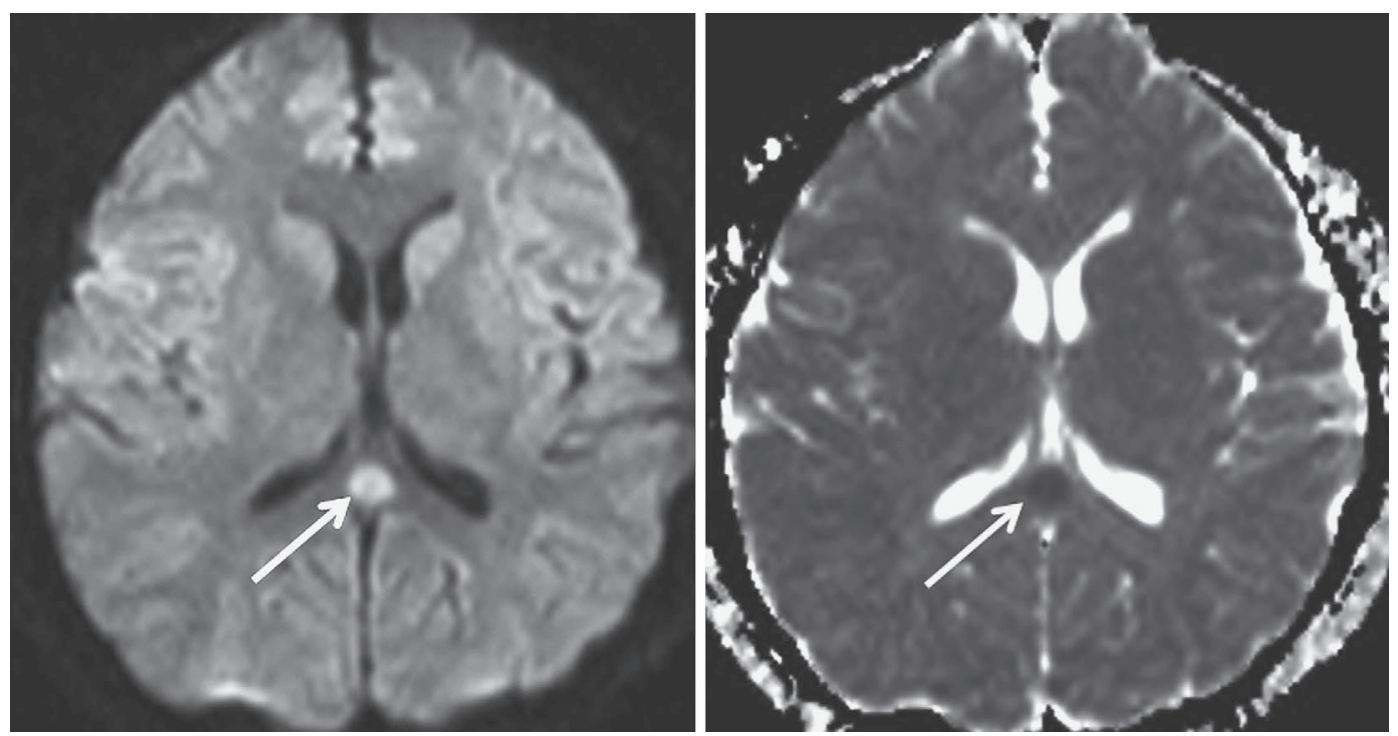

Picture 1.
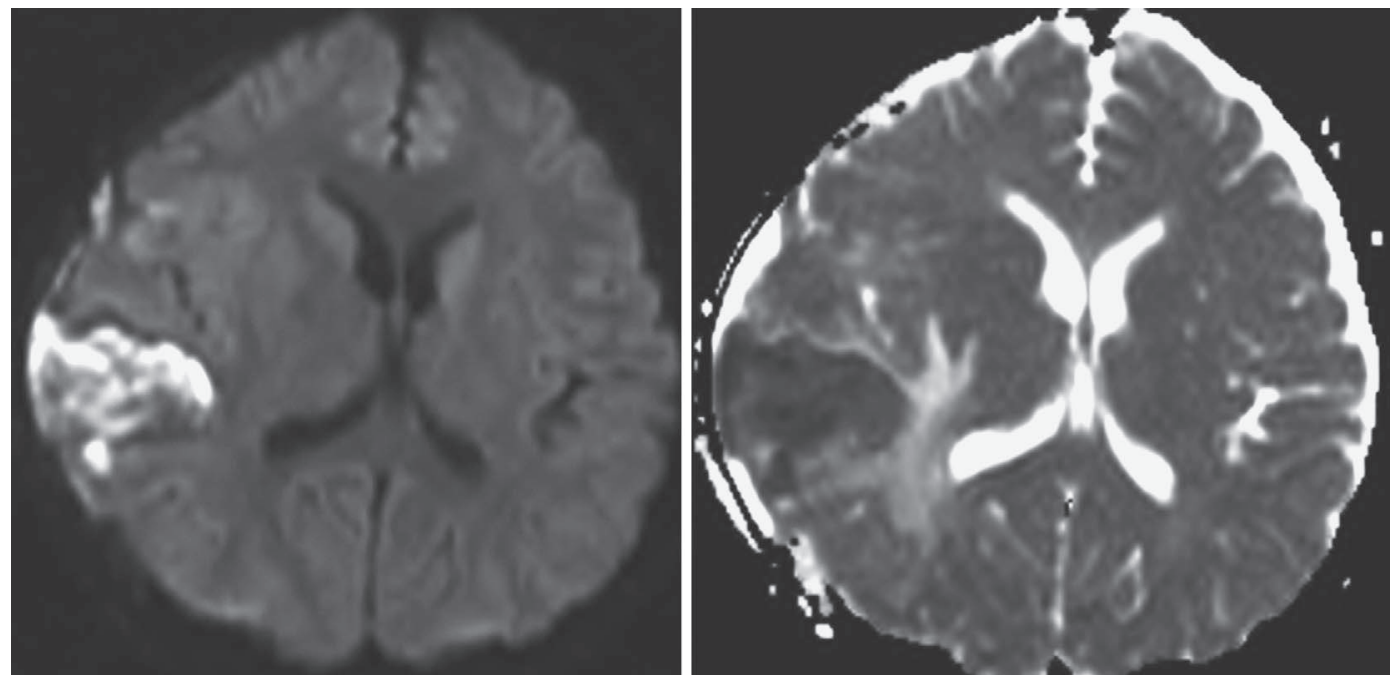

Picture 2.

${ }^{1}$ Department of Neurosurgery, National Defense Medical College, Japan and ${ }^{2}$ Department of Neurosurgery, National Hospital Organization Disaster Medical Center, Japan

Received for publication October 18, 2011; Accepted for publication October 26, 2011

Correspondence to Dr. Satoru Takeuchi, drne776@ndmc.ac.jp 
We previously reported a 20-year-old man who developed Epstein-Barr virus (EBV) hemorrhagic encephalitis (1). Briefly, he presented with a fever and headache (without seizures) and magnetic resonance imaging showed a focal lesion in the right temporal lobe. Antiviral, antibiotic, and antifungal treatment was started. However, computed tomography scan on day 2 revealed progression of the lesion, with hemorrhagic change, acute brain swelling, and a severe midline shift, and therefore he underwent a decompressive craniectomy. EBV DNA was identified in brain biopsy specimens. We retrospectively found that the diffusionweighted imaging on admission showed a high-intensity signal with a low apparent diffusion coefficient (ADC) value in the splenium of the corpus callosum (Picture 1, arrows), reflecting restricted diffusion due to cytotoxic edema. The abnormal signal in the splenium disappeared completely on day 16 (Picture 2). The previously reported etiologies of re- versible splenial lesions include hypoglycemia, alcoholism, malnutrition, electrolyte imbalances, anticonvulsant drug withdrawal, seizures, acute disseminated encephalomyelitis, and viral encephalitis. This is the second case of a transient lesion in the splenium caused by EBV encephalitis (2). The present case suggests that EBV infection should be considered in otherwise unexplained cases of splenial lesions.

The authors state that they have no Conflict of Interest (COI).

\section{References}

1. Takeuchi S, Takasato Y, Masaoka H, et al. Hemorrhagic encephalitis associated with Epstein-Barr virus infection. J Clin Neurosci 17: 153-154, 2010.

2. Hagemann G, Mentzel HJ, Weisser H, Kunze A, Terborg C. Multiple reversible MR signal changes caused by Epstein-Barr virus encephalitis. AJNR Am J Neuroradiol 27: 1447-1449, 2006.

(C) 2012 The Japanese Society of Internal Medicine http://www.naika.or.jp/imindex.html 